Correspondence to Dr Jon Stone, Department of Neurophysiologie Clinique/ Clinical Neurophysiology, University of Edinburgh, Western General Hospital, Edinburgh EH4 2XU, UK; Jon.Stone@ed.ac.uk

This article first appeared in Neurophysiologie Clinique/ Clinical Neurophysiology. ${ }^{1}$ It has been edited and updated for Practical Neurology but is largely the same article and is published here with thanks and permission of Dr Jean Michel-Guerit, editor of that journal as well as Elsevier.

Accepted 14 October 2015 Published Online First 29 December 2015

\section{SLinked}

- http://dx.doi.org/10.1136/ practneurol-2015-001242

CrossMark

To cite: Stone J. Pract Neurol 2016;16:7-17.

\title{
Functional neurological disorders: the neurological assessment as treatment
}

\author{
Jon Stone
}

\begin{abstract}
The neurologist's role in patients with functional disorders has traditionally been limited to making the diagnosis, excluding a 'disease' and pronouncing the symptoms to be 'non-organic' or 'psychogenic'. In this article, I argue that there are multiple opportunities during routine assessment of a patient with a functional disorder for the neurologist to take the lead with treatment. These opportunities occur throughout history taking, during the examination and, with greatest potential for treatment, at the end of the consultation. Elements of the neurologist's discussion that may be most useful include (a) emphasis that symptoms are genuine, common and potentially reversible; (b) explanation of the positive nature of the diagnosis (ie, not a diagnosis of exclusion); (c) simple advice about distraction techniques, self-help techniques and sources of information; (d) referral on to appropriate physiotherapy and/or psychological services; and (e) offering outpatient review. I also discuss how new diagnostic criteria for Diagnostic and Statistical Manual of Mental Disorders-5 and changes proposed for International Classification of Diseases may facilitate changes that allow neurologists to bring their management of patients with functional disorders in line with other multidisciplinary neurological disorders in the outpatient clinic
\end{abstract}

\section{INTRODUCTION}

Doctors in nearly all medical specialties see patients with physical symptoms that are genuine but cannot be explained on the basis of a recognised 'organic' disease. Around $30-50 \%$ of outpatient visits in primary and secondary care are for this reason. $^{2} 3$

Some specialties, such as gastroenterology, have developed a pragmatic approach to the diagnosis and treatment of their functional disorders such as irritable bowel syndrome and functional dyspepsia. ${ }^{4}$ Functional gastrointestinal disorders now occupy a standard part of their curriculum for training, practice and research. As a consequence, gastroenterologists have primary responsibility for the management of patients with these disorders, even though they may call on members of the multidisciplinary team to help.

Other specialties, such as cardiology and neurology, have not developed in the same way. Interest in this area from neurologists actually declined over the 20th century for many reasons. These include the success of the clinico-anatomic method, the dualistic split from psychiatry and prevailing notions that the diagnosis of 'conversion disorder' (requiring evidence of psychic conflict) and treatment (psychodynamic unravelling of the presumed conflict) were essentially the territory of psychiatry rather than neurology.

For most of the 20th century, the pendulum swung strongly towards a psychiatric model of functional disorder/ conversion disorder. However, in the last 10-20 years, the pendulum has started to swing back with increasing numbers of biological studies. It will hopefully come to rest on a model where both 'neurology and psychiatry', 'brain and mind' are equally important in considering the diagnosis and treatment of these disorders. ${ }^{6-8}$

In this article, I give a personal view regarding features of the neurological assessment that I believe the general neurologist can use for the day-to-day benefit of their patients with functional disorders. Some of this advice is evidence based, from prognostic or treatment studies, but much is not and derives from 15 years of subspecialty interest and referrals of patients, often perceived by colleagues to 
be 'difficult' or at the 'hard end' of the spectrum of functional neurological disorders.

My experience is that there are very few patients who are truly 'difficult' to have a consultation with. Many consultations are time consuming. Many patients give 'wandering' histories that need frequent 'reining in' and considerable patience. There are many patients whom I have been unable to help. But with only a couple of exceptions the 'recipe' presented here creates consultations that virtually never result in an angry or complaining patient, even though this is a common scenario in many neurology services. ${ }^{9}$ Sometimes, single consultations have been highly therapeutic without needing any other intervention. In many others, consultations appear to have helped patients make improvements and to work more effectively with other health professionals. Even when a patient's symptoms and disability remain the same, I am struck how often patients with functional disorders report 'peace of mind' and improved quality of life after developing a good understanding of their diagnosis. I'm aware that a 'recipe' on a printed page may not be enough. Some colleagues of mine appear to 'say the right things' but still have unhappy patients, perhaps because those colleagues rushed the consultation or do not fundamentally believe that the patient has anything much the matter with them. When some of my neurologist colleagues 'roll their eyes' or make comments such as, "No, I think she is genuine/real" (ie, not functional), they are reminders of the professional ambiguity that characterises views about whether patients with functional disorders are deserving of help or not. ${ }^{10}$

The suggestions here allow a model of care, like those in gastroenterology, where functional disorders such as migraine or multiple sclerosis become part of the accepted repertoire of conditions that a neurologist diagnoses and then takes responsibility for managing. Here I am arguing that, as with those conditions, the neurological assessment should not be regarded as a prelude to treatment, but the first stage of treatment itself. ${ }^{11}$

For a systematic description of terminology, ${ }^{12}$ components of the assessment ${ }^{13}$ and pitfalls in diagnosis, ${ }^{14}$ I direct the reader elsewhere.

\section{THERAPEUTIC ELEMENTS OF HISTORY TAKING}

The purpose of taking a history is not just to obtain information-ideally, it also enables the patient to feel unburdened and to gain confidence in the doctor before the diagnosis has even been discussed.

Patients with functional disorders have often had bad experiences with previous doctors. Some common reasons for this include

- not getting a chance to describe all their symptoms;

- feeling that their symptoms were being 'dismissed' or that they were 'disbelieved';

- a perception that the doctor was most interested in looking for some kind of psychological problem upon which to 'pin' the symptoms (when it did not feel like that was the case to the patient and indeed there may not have been one to find);

- not being given a chance to explain and discuss what thoughts they had about the cause and treatment of the symptoms (eg, Lyme disease, 'crumbling bones' or stroke);

- not being given a diagnosis, treatment or anything that they can read about afterwards;

- not being given enough time.

To this familiar list I would add that patients with acute functional motor symptoms or dissociative (non-epileptic) attacks commonly experience depersonalisation (a feeling that they are disconnected from their body) or derealisation (a feeling of being disconnected from their surroundings) in conjunction with the onset of their symptoms (or with their attacks). ${ }^{15-17}$ Patients often find it hard to describe dissociative symptoms because (a) they may lack the words for the symptoms and (b) they worry that the symptoms sound 'crazy'. Conversely, explaining that these terms are medical words for a common 'trancelike state' that has nothing to do with 'going crazy' can be both therapeutic and helpful for explaining the mechanism of symptoms.

With these 'bad experiences' in mind, here are some suggestions for therapeutic aspects of history taking.

1. 'Drain the symptoms $d r y$ '-Asking the patient to make a list of all their symptoms does not take as long as you think. It may seem perverse to want to ask about fatigue, sleep disturbance, pain, poor concentration and dizziness in someone who has already volunteered eight symptoms. However, a complete list of current symptoms at the start of a consultation helps a patient to feel unburdened and prevents symptoms 'popping up' later on (eg, when they are leaving the room). Questions about fatigue and sleep often reveal that these are the main problems-the patient may be relieved to be asked about them as they may have expected that the doctor would not wish to hear from a patient who is 'tired all the time'.

2. Asking about dissociation-Obtaining a history of depersonalisation and derealisation may require questions that are slightly more 'leading' than normally advised. Often patients say they have not had any symptoms at the onset of acute functional motor symptoms or dissociative (non-epileptic) attacks. ${ }^{18}$ They will, however, often admit to symptoms of dissociation or panic if asked by questionnaire $^{19}$ or in the right way during assessment. ${ }^{1720}$ Questioning might proceed as in box 1 .

Hopefully it can be seen from this exchange that the patient has unburdened themselves of a frightening symptom that initially they were reluctant (or found hard) to discuss and received a preliminary explanation that it is common and has nothing to do with 'being crazy'. As I will explain later, it is often the patient's perceived failure to obtain recognition that the symptoms are 'real' and 'not crazy' that so often forms the largest 
Box 1 Discussing dissociation during the history in a way that is therapeutic for the patient

Doctor: Did you get any warning symptoms before your blackout?

Patient: No doctor, none.

Doctor: Did you feel dizzy when it started, even just for a few seconds?

Patient: A bit maybe.

Doctor: What was the dizziness like?

Patient: I don't know really-it's hard to describe.

Doctor: If I told you there are three main sorts of dizziness-a lightheaded feeling that you might faint, a feeling that you are moving even though you are still and a spaced out feeling as if you were not quite there -which of these would you say it was most like?

Patient: The third one and the first one

Doctor: Tell me about that spaced out feeling in your own words. Don't worry about sounding silly. The more detail you can give me, the more I can help.

Patient: Well it was strange really-it was like I was floating and people around me were really far away. It was horrible.

Doctor: How long did it go on for?

Patient: It must have been a couple of minutes

Doctor: Was it scary? Did it get scarier as time went on?

Patient: Yes it was really frightening —It felt like I was going crazy...

Doctor: Actually what you are describing is called dissociation-it's nothing to do with going crazy at all. It's a trance like state that people often have when they develop symptoms-I'll explain later.

barrier to successful rehabilitation and good outcome. $^{21}$ Providing early reassurance that the consultation is not heading down the path of the patient being labelled as 'crazy' puts the patient at ease and into a state where they may find it easier to discuss other aspects of the history.

3. Ask what the patient thinks is wrong and what should be done-Medical students (in the UK at least) are now taught to routinely ask about 'Ideas, Concerns and Expectations' although this is a habit that has passed by many older doctors. But these lines of questioning are essential in allowing the neurologist's explanation to be tailored to the patient's prior concerns. Therefore, someone who thinks their bones are crumbling in their neck and has been unhelpfully told by their general practitioner that they have cervical spondylosis will need a discussion of what a normal MR scan of cervical spine looks like at the age of 40. A patient who believes they have Lyme disease or multiple sclerosis will require something different. This discussion becomes therapeutic when the patient or family experiences relief in getting their worst fears and concerns out into the open. The patient who is adamant that they will never improve is likely to have a worse prognosis than the patient who is unsure and looking for answers. ${ }^{21} 22$

4. What happened with the other doctors?-When asked what they think is wrong, many patients will say, "I don't know", despite a documented previous discussion of the diagnosis of a functional disorder. Why did the patient not believe the first explanation? Allow the patient to vent their frustration at previous health encounters. You do not need to pass judgement on what happened, but the patient is likely to find this discussion therapeutic.

5. Go easy on 'psychological' questions-Neurologists are often tempted to dive in to questions about depression, anxiety, stress or abuse because they have been conditioned to believe that this is the right thing to do. It is actually not necessary to ask the patient about their mood and levels of anxiety, either to make a diagnosis or to begin treatment. Studies show that only around half of the patients have a comorbid anxiety or depression. Such things can often be inferred anyway from questions about day-to-day activities, for example, if they look forward to watching 'Top Gear' on television, then they probably are not depressed (or demented). Patients with functional motor symptoms have rates of recent life stress and prior abuse not much different to the general population. ${ }^{23}$ Questions about prior psychological trauma such as physical and sexual abuse are likely, in any case, to be unnecessarily intrusive for a first assessment unless it is clear that the patient wishes to discuss it. If these things do need to be discussed, most patients prefer to discuss them once they have confidence in the doctor and the diagnosis (ie, at a second appointment). Premature and clumsy questioning is commonly 'antitherapeutic' by raising suspicion in the patient that you think their symptoms are 'all in the mind' (even if that is not what you think!). In many patients though, it is quite straightforward and reasonable to ask about depression and anxiety as part of a systems enquiry. Instead of asking blunt questions like, "Are you depressed/anxious?", it may be more helpful to ask, "Do your symptoms get you down/make you worried?". The core of generalised anxiety is excessive worry that the person finds difficult to control. Instead of asking, "Do you have panic attacks?" (patients may, but not recognise them as such), ask, "Do you have attacks where you have lots of symptoms all at once-is that scary?".

6. Time-Probably the hardest problem to solve from my initial list of patient 'bad experiences' is not having enough time. Ideally the patient with complex and chronic functional disorders should be given at least an hour for a new patient assessment, especially if they have seen many other specialists. In many neurological services, this is not possible. This compromises what can be delivered, but in my own practice I still think most of these components can be fitted in to a $30 \mathrm{~min}$ consultation (and I do have to do that as well!). It may be worth reflecting though that a neurosurgeon does not try to remove someone's pituitary gland in the same time they would expect to decompress a 
carpal tunnel and perhaps neurologists should be less rigid about spending the same time with every patient.

\section{THERAPEUTIC FEATURES OF THE EXAMINATION Showing patients their positive signs}

The diagnosis of functional neurological disorders should be made on the basis of positive features on the examination, not on the absence of disease (table 1). ${ }^{24-26}$

Something that follows on from this is that functional disorders can also be diagnosed in the presence of existing disease such as multiple sclerosis or Parkinson's disease. ${ }^{34-36}$ Sticking to this rule with patients is important in avoiding diagnostic mistakes but also therapeutic in helping patients to understand they do not have an absence of a condition (ie, nonorganic), they have a positively identifiable condition with positive criteria.

In an article entitled 'Trick or Treat?: showing patients with functional (psychogenic) motor symptoms their signs, ${ }^{37}$ Mark Edwards and I argued that sharing physical signs such as Hoover's sign and the tremor entrainment test with patients fulfilled several valuable functions.
1. The diagnosis is positive and not negative. It is a clinical bedside diagnosis and not a diagnosis made because a scan is normal. Indeed, the scan may be abnormal and it may still be a functional tremor. These positive signs are now required to make a diagnosis of functional neurological disorders in Diagnostic and Statistical Manual of Mental Disorders-5 (DSM-5). ${ }^{38}$ The presence of psychological stressors is no longer required. I discuss DSM-5 at the end of this article.

2. The signs demonstrate the potential for reversibility-for example, hip extension returns transiently to normal during contralateral hip flexion against resistance.

3. The signs demonstrate the role of attention and the benefit of distraction-for example, the more the patient pays attention to the limb and tries to move it the worse it is. Conversely, when they are distracted the movement is much better.

We find in our own practice that this simple demonstration of the nature of the diagnosis is one of the most therapeutic parts of the consultation. Our patients even practice these physical signs at home to help to persuade themselves and family members that the diagnosis is correct. It is perhaps then worth rehearsing what the explanation of a Hoover's sign would sound like during a consultation as shown in box 2 .

Table 1 Examples of positive signs in functional disorders that can be shared with a patient to explain the diagnosis

\begin{tabular}{|c|c|}
\hline & Positive finding \\
\hline \multicolumn{2}{|l|}{ Motor symptoms } \\
\hline Hoover's sign ${ }^{27}$ (figure 1) & Hip extension weakness that returns to normal with contralateral hip flexion against resistance \\
\hline Hip abductor $\operatorname{sign}^{28}$ & Hip abduction weakness returns to normal with contralateral hip abduction against resistance \\
\hline Other clear evidence of inconsistency & For example, weakness of ankle plantar flexion on the bed but able to walk on tiptoes \\
\hline Global pattern of weakness & Weakness that is global, affecting extensors and flexors equally \\
\hline \multicolumn{2}{|l|}{ Movement disorder } \\
\hline Tremor entrainment test ${ }^{29}$ & $\begin{array}{l}\text { Patient with a unilateral tremor is asked to copy a rhythmical movement with their unaffected limb: the } \\
\text { tremor in the affected hand either 'entrains' to the rhythm of the unaffected hand, stops completely or } \\
\text { the patient is unable to copy the simple rhythmical movement }\end{array}$ \\
\hline Fixed dystonic posture ${ }^{30}$ & $\begin{array}{l}\text { A typical fixed dystonic posture, characteristically of the hand (with flexion of fingers, wrist and/or elbow) } \\
\text { or ankle (with plantar and dorsiflexion) }\end{array}$ \\
\hline $\begin{array}{l}\text { Typical 'functional' hemifacial overactivity } \\
\text { (figure 2) }\end{array}$ & $\begin{array}{l}\text { Orbicularis oculis or orbicularis oris over-contraction, especially when accompanied by jaw deviation and/ } \\
\text { or ipsilateral functional hemiparesis }\end{array}$ \\
\hline \multicolumn{2}{|l|}{ Balance/gait } \\
\hline Reduced postural sway with distraction ${ }^{32}$ & $\begin{array}{l}\text { Abnormal sway that resolves during tasks such as assessing numbers written on the back or using a } \\
\text { phone }\end{array}$ \\
\hline \multicolumn{2}{|l|}{ Non-epileptic attacks ${ }^{26}$} \\
\hline $\begin{array}{l}\text { Prolonged attack of motionless } \\
\text { unresponsiveness }\end{array}$ & Paroxysmal motionlessness and unresponsiveness lasting longer than a minute \\
\hline Long duration & Attacks lasting longer than 2 min without any clear cut features of focal or generalised epileptic seizures \\
\hline Closed eyes & Closed eyes during an attack, especially if there is resistance to eye opening \\
\hline Ictal weeping & Crying either during or immediately after the attack \\
\hline Memory of being in a generalised seizure & Ability to recall the experience of being in a generalised shaking attack \\
\hline $\begin{array}{l}\text { Presence of an attack resembling epilepsy } \\
\text { with a normal EEG }\end{array}$ & $\begin{array}{l}\text { A normal EEG does not exclude frontal lobe epilepsy or deep foci of epilepsy but does provide supportive } \\
\text { evidence }\end{array}$ \\
\hline \multicolumn{2}{|l|}{ Visual symptoms ${ }^{33}$} \\
\hline Fogging test & $\begin{array}{l}\text { Vision in the unaffected eye is progressively 'fogged' using lenses of increasing dioptres whilst reading an } \\
\text { acuity chart. A patient who still has good acuity at the end of the test must be seeing out of their } \\
\text { affected eye }\end{array}$ \\
\hline Tubular visual field & The patient has a field defect of the same width at $1 \mathrm{~m}$ as at $2 \mathrm{~m}$ \\
\hline
\end{tabular}




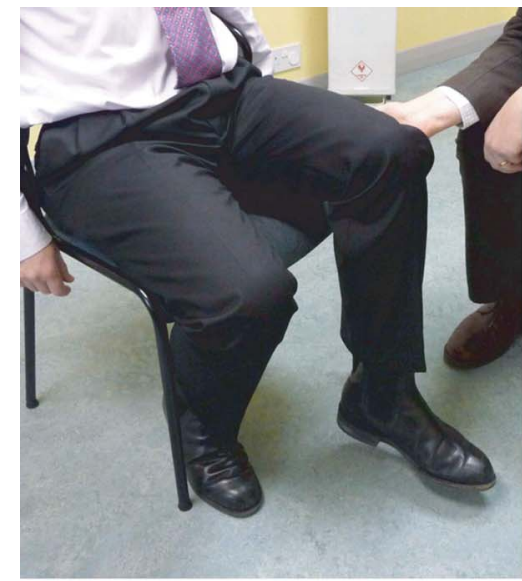

Test hip extension - it's weak

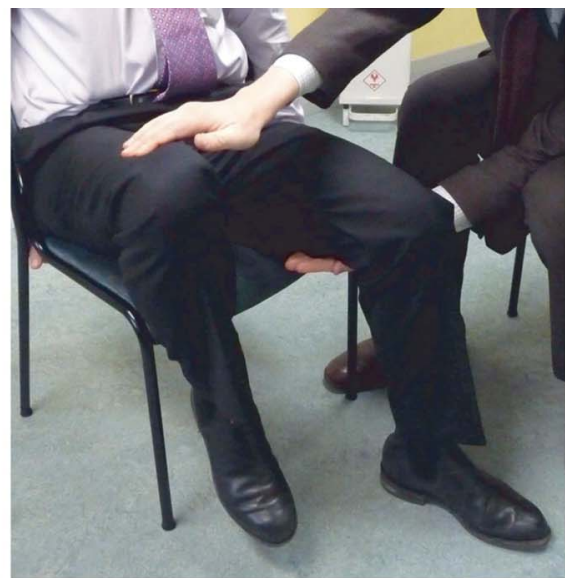

Test contralateral hip flexion against resistance - hip extension has become strong

Figure 1 Hoover's sign of functional leg weakness. Reproduced with permission from BMJ publications. ${ }^{13}$

\section{A 'HANDS ON' WAY OF IMPROVING DOCTOR PATIENT RAPPORT}

We live in an age of technological medicine, but many patients still appreciate the thoroughness and skill of a physical examination. The physical examination provides 'hands on' contact, a basic transaction that patients have expected from health professionals for millennia. There are also many aspects of the neurological examination that have the potential to 'break the ice', such as the plantar response, finger-nose test and knee jerks. The opportunity to share a smile with a patient whose affect has been flat throughout an assessment should not be underestimated.

\section{AN OPPORTUNITY TO REINFORCE NORMAL FINDINGS}

During the examination, some doctors say very little. Explaining what you are doing and mentioning that things are normal as you go along helps improve confidence and transparency.

These aspects of the physical examination are therapeutic opportunities open to physicians and physiotherapists but which psychologists and psychiatrists rarely avail themselves of. There is no reason, however, why these professionals should not also learn selected skills. Psychiatrists I work with have successfully incorporated these features into their practice.

\section{THERAPEUTIC ASPECTS OF THE EXPLANATION}

Diagnoses and explanations in medicine are often, in themselves, therapeutic. The patient with migraine will be less likely to worry about a brain tumour when they realise that pain from a brain tumour would not remit as well as relapse. Even patients with motor neurone disease who are devastated and shocked at the news of a terminal illness may report a sense of relief that a cause has been found for their problems. Diagnostic limbo is a difficult state for anyone to be in.

\section{COMMON APPROACHES}

Neurologists who are confident about the diagnosis of a functional disorder are often less confident about transmitting that information to the patient. There are
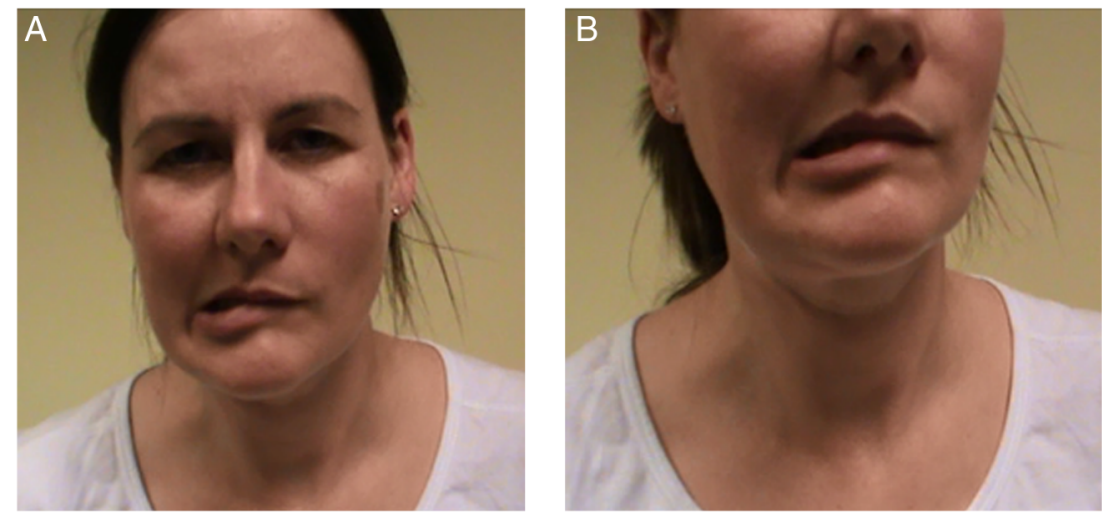

Figure 2 Functional facial overactivity can look like facial weakness - typically with platysma overactivity, jaw deviation and/or contraction of orbicularis oculis. Reproduced with permission from Stone J. ${ }^{1}$ 
Box 2 An example of how to show a patient their Hoover's sign ${ }^{37}$

Doctor (testing weak hip extension): Try to keep your foot flat on the floor for me.

Patient (in a sitting position): I can't do it.

Doctor (testing contralateral hip flexion against resistance but holding other hand under the patient's weak thigh): Now, concentrate on lifting up your good right leg. Look at that right leg and focus on keeping it up in the air. Now, can you feel that when you do that, the power in your left leg has come back to normal? I can't get that left foot off the floor now.

Patient (and the partner): That's weird.

Doctor: This test is called Hoover's sign. It's a positive sign of a genuine problem called functional leg weakness. I can see that you were really trying to keep your left foot on the floor but your leg was weak. But because the movement comes back to normal when you move your other leg, that shows me that the weakness can't be due to damage anywhere in the nervous system. Patient: So what's going on then?

Doctor: Your brain is having trouble sending a message to your leg to make it move, but when you are distracted the automatic movements can take place normally. This test shows me that there is a problem with the function of your nervous system, not damage to it. It's basically a problem with the function of the nervous system-a bit like a software problem instead of a hardware problem. Shall I show you again?

several common approaches to this problem. It is worth rehearsing the pitfalls of each of these approaches (table 2).

\section{GIVING A POSITIVE DIAGNOSIS}

One solution to these problems is to approach the problem in the same transparent and straightforward way you do for other patients seen in the neurology clinic (table 3). Discussions about terminology go round and round ${ }^{124041}$ (and probably always will). I increasingly find that is not so much the precise terminology but the overall attitude of the doctor that matters.

Consider how you tell a patient that they have multiple sclerosis. Generally you start, within the first few sentences at least, by telling the patient that they have multiple sclerosis. There is then usually a discussion about why the diagnosis has been made-typical symptoms, signs on examination and an abnormal MRI that a doctor will preferably show to the patient. The conversation does not start with a discussion about all the neurological diseases the patients do not have (although that may come later). Neither does the conversation typically move early towards aetiology, which for most conditions is not found in the name of the disorder. The doctor may talk about inflammation or autoimmune disease but this is mechanism not aetiology-'how' not ' $w h y$ '. When doctors do discuss aetiology, then normally phrases such as, "It's just one of those things/bad luck", indicate to the patient that it is not their fault. It is also true that if you can see it on a scan or have heard of the condition then generally patients do not believe a priori that it is their fault anyway.

Following this initial discussion, the patient with multiple sclerosis or epilepsy may be directed to sources of information on the web and, with a bit of luck, an appointment with a specialist nurse so that they can have support and further information for their chronic condition. Patients with chronic conditions like diabetes and epilepsy are encouraged to selfmanage and optimise their conditions, but the neurologist or another physician will see the patient from time to time for review, active treatment where appropriate, and certainly in the case of multiple sclerosis, at least once more to answer questions.

So, translating this approach to functional disorders gives us a plan outlined in table 3 . Tell the patient what they have first (and discuss what it is not later). Discuss the positive evidence for the diagnosis from the history and examination and explain why it cannot be seen on any scans. Some discussion of mechanism is helpful-a problem with the software of the brain communicating to the limbs (functional motor disorders) or a trancelike state (dissociative (non-epileptic) attacks)—especially when linked to the examination findings or symptoms of dissociation. If the question of 'why' arises, then it would seem quite reasonable to say that this varies from person to person, that there are various triggers including injury, pain, panic attacks and life stress but that in many people it is not clear and may well be 'one of those things'.

As with other chronic disease management, being honest and transparent, encouraging the patient to understand their condition, providing self-help information (such as http://www.neurosymptoms.org or http://www.nonepilepticattacks.info) and optimising function are important. Specialist nurses or allied health professionals dedicated to this area hardly exist but would be a great advantage, given the size and complexity of the problem.

If your current approach to talking to patients with functional disorders is different from how you approach other disorders, it is worth asking yourself why. Do you have an ambivalent attitude to the patient and a concern that the symptoms are voluntary? Are you changing your approach because you think they need a psychosocial formulation on the first assessment? Or perhaps you view these patients as 'not having a diagnosis' rather than having a diagnosis? 
Table 2 Features of some common explanations offered by neurologists to patients for functional disorders and their associated problems

\begin{tabular}{|c|c|}
\hline Strategy & Comments \\
\hline $\begin{array}{l}\text { 1. Making no diagnosis: no neurological disease (includes the term } \\
\text { 'non-organic') }\end{array}$ & The patient is likely to go elsewhere to seek a diagnosis \\
\hline $\begin{array}{l}\text { 2. Making an 'unexplained' diagnosis, eg, these things are common in } \\
\text { neurology and we don't really know why they happen }\end{array}$ & $\begin{array}{l}\text { The patient is likely to go elsewhere to seek a diagnosis } \\
\text { Many neurological disorders have known pathology 'unexplained' or } \\
\text { 'unknown' cause, eg, multiple sclerosis/Parkinson's disease } \\
\text { to marologists should be familiar with functional disorders and be able } \\
\text { to mitive clinical diagnosis, eg, migraine/Parkinson's disease }\end{array}$ \\
\hline $\begin{array}{l}\text { 3. Making an incomplete diagnosis_eg, telling someone with a 3-week } \\
\text { history of functional hemiparesis triggered by migraine that they just } \\
\text { have migraine }{ }^{39}\end{array}$ & $\begin{array}{l}\text { This may be acceptable to the patient (and be easier for the neurologist) but } \\
\text { leads to a missed opportunity to understand symptoms and their potential for } \\
\text { reversibility }\end{array}$ \\
\hline $\begin{array}{l}\text { 4. Trying to explain that the problem is psychological-eg, explaining } \\
\text { that these symptoms are often 'stress-related' }\end{array}$ & $\begin{array}{l}\text { Likely to be rejected by most ( } 80 \%) \text { of patients } \\
\text { 'maften equated by patients as an accusation that the symptoms are } \\
\text { 'many patients with these symptoms do not have identifiable stress or } \\
\text { psychiatric disorder } \\
\text { This is, however, consistent with referral for psychological treatment }\end{array}$ \\
\hline 5. Making a functional diagnosis & $\begin{array}{l}\text { Consistent with a disorder of nervous system functioning } \\
\text { Does not leap to conclusions about the cause } \\
\text { Could be interpreted as something irreversible that cannot be } \\
\text { improved with physical or psychological rehabilitation. }\end{array}$ \\
\hline
\end{tabular}

Table 3 Some suggested ingredients for a therapeutic explanation for patients with functional neurological disorders

\begin{tabular}{|c|c|}
\hline Ingredient & Example \\
\hline Explain what they do have... & $\begin{array}{l}\text { "You have functional weakness" } \\
\text { "You have dissociative seizures" }\end{array}$ \\
\hline $\begin{array}{l}\text { Emphasise the mechanism of the symptoms rather } \\
\text { than the cause }\end{array}$ & $\begin{array}{l}\text { Weakness: "There is a problem with the way your brain is sending messages to your body—its a } \\
\text { problem with the function of your nervous system" } \\
\text { Seizures: "You are going into a trance-like state a bit like someone being hypnotised" }\end{array}$ \\
\hline Explain how you made the diagnosis & Show the patient their Hoover's sign or dissociative seizure video \\
\hline Indicate that you believe them & "I do not think you are imagining/making up your symptoms/mad" \\
\hline Emphasise that it is common & "I see lots of patients with similar symptoms" \\
\hline Emphasise reversibility & "Because there is no damage, you have the potential to get better" \\
\hline Explain what they do not have & "You don't have multiple sclerosis, epilepsy", etc \\
\hline Emphasise that self-help is a key part of getting better & "This is not your fault but there are things you can do to help it get better" \\
\hline Metaphors may be useful & "There's a problem with the software of the nervous system rather than the hardware" \\
\hline Introducing the role of depression/anxiety & $\begin{array}{l}\text { "If you have been feeling stressed/low/worried, that will tend to make the symptoms even } \\
\text { worse" (often easier to achieve on a second visit) }\end{array}$ \\
\hline Use written information & $\begin{array}{l}\text { Send the patient their clinic letter. Give them some written information, eg, http://www. } \\
\text { neurosymptom.org, http://www.nonepilepticattacks.info }\end{array}$ \\
\hline Stop the antiepileptic drug in dissociative seizures & $\begin{array}{l}\text { If you have diagnosed dissociative (non-epileptic) attacks and not epilepsy, stop the antiepileptic } \\
\text { drug }\end{array}$ \\
\hline See the patient again & $\begin{array}{l}\text { "I'll see you again. Please have a read of my letter and the information I have given you and } \\
\text { come back with questions" }\end{array}$ \\
\hline $\begin{array}{l}\text { Making the physiotherapy or psychiatric referral } \\
\text { (preferably at a second visit) }\end{array}$ & $\begin{array}{l}\text { "My colleague X (or my colleague } \operatorname{Dr} X \text { ) has a lot of experience and interest in helping patients } \\
\text { with functional movement disorder-he won't think you are crazy either" }\end{array}$ \\
\hline
\end{tabular}

\section{ARRANGING A FOLLOW-UP VISIT}

Table 3 also expands on other things that might be said by a neurologist during a $5-10 \mathrm{~min}$ period at the end of a consultation. In addition to explanation, the neurologist treating functional disorders like multiple sclerosis or epilepsy would normally see the patient again to go over the diagnosis. At that second visit, if the first one has gone well, other issues may emerge and referral to physiotherapy or psychiatry is likely to flow more naturally from the consultations. If the first consultation did not go well, this might be because the patient needs more time to understand it, or it 
might be that the patient is fundamentally not motivated or interested to pursue the diagnosis and treatment suggested. If that is the case, then it would be sensible for the neurologist to defer referral to other services on the grounds that they are unlikely to be able to help someone who does not have some confidence in their diagnosis (see below). Either way, a follow-up visit from a neurologist can play a useful role in determining who might benefit from more treatment and who probably will not. A follow-up visit also allows a neurologist the chance to learn from experience by finding out when they have communicated well and when they have not.

\section{NEUROLOGISTS CAN DO COGNITIVE-BEHAVIOURAL THERAPY}

Physicians often believe that cognitive-behavioural therapy is a rather complex 'black box' treatment that only trained therapists can carry out. In fact, when a neurologist alters a patient's view about their diagnosis during a single consultation (eg, the patient came in thinking it was multiple sclerosis/brain damage and left believing they had a functional disorder and potential for recovery) then that is cognitive therapy. If the patient then changes their behaviour as a result of their new cognition, then that is cognitivebehavioural therapy. Arguably, a neurologist is better placed than anyone else to shift fundamental misconceptions that a patient may have about their diagnosis.

In addition to altering basic beliefs about their disorder, neurologists are in a position to offer simple tips for rehabilitation. For example, they can explain about doing more on bad days and less on good days, using distraction techniques during movement (with music, talking, altered gait pattern) or distraction techniques before a dissociative (non-epileptic) attack.

\section{STEPPED CARE FOR FUNCTIONAL NEUROLOGICAL DISORDERS}

A group of health professionals working in this area in Scotland proposed a stepped-care model for treating patients with functional neurological disorders. Step 1 of treatment is the neurological consultation model described here. ${ }^{42}$ The neurologist then has a key role in triaging and making onward referrals to the multidisciplinary team, which ideally involves physiotherapy, psychiatry/psychology, speech therapy and occupational therapy. My personal preference for step 2 is a brief intervention either by a physiotherapist (for functional motor symptoms) or psychologist (for non-epileptic attacks). Step 3 is more complex multidisciplinary treatment.

Describing further treatment with physiotherapy ${ }^{43-45}$ and/or psychological treatments ${ }^{46-48}$ is beyond the scope of this article. In brief though, there are now detailed recommendations regarding the content of physiotherapy ${ }^{45}$ and there is good evidence emerging for its role in treating patients with functional movement and gait disorder. For example, a recent randomised trial of 3 weeks of inpatient physical rehabilitation for patients with functional gait disorder of 9 months duration showed a mean 7-point change in a 15 -point functional mobility scale compared with controls. ${ }^{49}$ Another prospective study of 47 patients with a 5 -year history of symptoms undergoing similar physically oriented 5-day physical treatment (with no formal psychological treatment) recorded a good outcome in $55 \%$ at follow-up. ${ }^{50}$ Cognitive-behavioural therapy was shown to be a promising treatment for patients with dissociative (non-epileptic) attacks in a randomised-controlled trial with a number needed to treat of 5 , and there is a UK multicentre trial ongoing (http://www.codestrial.org). ${ }^{47}$ Multidisciplinary care also now has some evidence base. ${ }^{48} 51-53$

\section{WHEN TREATMENT FAILS}

The implication of a stepped-care approach is that if the first step-the neurological assessment and explanation-fails, then there is no foundation upon which to build further treatment. Psychologists and physiotherapists who work with these patients often comment how hard their jobs are when the initial neurological consultation has gone badly and the patient still believes they are a 'medical mystery'. Conversely, further therapy appears much easier when the patient has some understanding of their diagnosis, especially its potential for reversibility. ${ }^{43}$ In some patients, reiteration of that first step by the neurologist may improve the situation. However, a substantial proportion of patients cannot understand or accept their diagnosis or benefit from treatment, however carefully and sympathetically it is explained to them. Common features of patients in whom treatment fails include:

- inability to repeat back anything about their diagnosis on the second visit after a sympathetic initial consultation;

- personality disorder;

- very fixed views about an alternative diagnosis;

- the presence of a legal case;

- very longstanding and/or physically disabling symptoms.

Clinicians should be cautious with this list as many patients with these features can be helped. It is also important to recognise, however, that there is a group of patients with functional disorders who do understand their diagnosis, do comply with treatment but do not have much improvement.

It is important for all health professionals to recognise when treatment has not helped or is not going to help. It is not fair to ask a patient or therapist to continue treatment that will probably fail and be demoralising for both parties. Instead, neurologists should be willing at times to acknowledge that, as with many neurological disorders, they do not currently have a treatment that can help the underlying symptom and 
they should focus instead on enabling the patient and protecting them from harm. In my own practice, I say to the patient that I am sorry I cannot help their underlying condition and that I do not regard this as their fault. For some patients in this situation, aids such as wheelchairs or house adaptations are appropriate, even though these should be avoided in the patient with rehabilitation potential. My views are similar with respect to disability financial benefits. They are appropriate for patients who are genuinely disabled, regardless of the cause, but may create an obstacle to recovery in those who are on a pathway to recovery (whether they have a functional disorder or multiple sclerosis). These things can be discussed explicitly with the patient. A blanket approach of viewing disability benefits as inappropriate for patients with functional disorders is not correct in my view or in the view of the UK Department of Work and Pensions. I ask the patient's primary care physician to monitor for comorbid treatable conditions, such as depression or anxiety, and will offer to review if there are new neurological symptoms causing concern.

\section{CLASSIFICATIONS: RECENT CHANGES AND IMPLICATIONS FOR PRACTICE}

The diagnostic criteria for functional neurological disorders in the DSM- $5^{38}$ emphasise the importance of positive physical criteria in making the diagnosis (box 3). Patients no longer must have had recent psychological stressor (even though some will have). These new criteria bring the diagnosis of functional disorders back into a form that neurologists should be comfortable with using. In addition, the International Classification of Diseases (ICD), tenth revision is also being revised for its 11th edition in 2017. For the first time, functional neurological disorders should appear in the neurology section as well as in the psychiatry section. ${ }^{54} 55$ One of the hopes of these revised international criteria is that they will encourage greater confidence in the

Box 3 Diagnostic and Statistical Manual of Mental Disorders -5 criteria for conversion disorder (functional neurological symptom disorder)

1. One or more symptoms of altered voluntary motor or sensory function.

2. Clinical findings provide evidence of incompatibility between the symptom and recognised neurological or medical conditions.

3. The symptom or deficit is not better explained by another medical or mental disorder.

4. The symptom or deficit causes clinically significant distress or impairment in social, occupational or other important areas of functioning or warrants medical evaluation. diagnosis from neurologists and better interdisciplinary working between neurology and psychiatry.

\section{CONCLUSION}

Neurologists have always been the primary doctors responsible for making a diagnosis of functional neurological disorders. In contrast, they often do not take responsibility for treatment. I have argued that there are multiple opportunities within a routine history taking, examination and explanation to begin therapy for the patient with a functional disorder. A method of explanation that simply mirrors that used for other neurological conditions may be best. This emphasises what the problem is (and not what it is not), why the diagnosis is being made, emphasises reversibility but does not depend on aetiological assumptions that may be incorrect. A successful consultation should be the beginning of treatment, not the prelude to treatment. New diagnostic criteria and structures in DSM-5 and ICD-11 will hopefully encourage neurologists to regain responsibility for the management and not just the diagnosis of functional neurological disorders.

\section{Take home messages}

- The neurological assessment for functional disorders can be the start of treatment, not just a prelude to diagnosis.

- Make a diagnosis based on positive signs and share them with the patient.

- Effective explanation, by a neurologist can alter key cognitions and behaviours in patients with functional disorders.

- Neurologists have a role in triaging to both physiotherapy and psychotherapy evidence-based treatment.

Funding JS is supported by an NHS Scotland Career Research Fellowship.

Competing interests JS runs a free self-help website www. neurosymptoms.org mentioned in this article. He makes no money from the site.

Provenance and peer review Commissioned. Externally peer reviewed. This paper was reviewed by Mark Edwards, London, UK.

\section{REFERENCES}

1 Stone J. Functional neurological disorders: the neurological assessment as treatment. Neurophysiol Clin 2014;44:363-73.

2 Stone J, Carson A, Duncan R, et al. Who is referred to neurology clinics?--the diagnoses made in 3781 new patients. Clin Neurol Neurosurg 2010;112:747-51.

3 Nimnuan C, Hotopf M, Wessely S. Medically unexplained symptoms: an epidemiological study in seven specialities. J Psychosom Res 2001;51:361-7. 
4 Drossman DA. The functional gastrointestinal disorders and the Rome III process. Gastroenterology 2006;130:1377-90.

5 Stone J, Hewett R, Carson A, et al. The 'disappearance' of hysteria: historical mystery or illusion? J R Soc Med 2008;101:12-18.

6 Edwards M, Bhatia K. Functional (psychogenic) movement disorders: merging mind and brain. Lancet Neurol 2012;11:250-60.

7 Edwards MJ, Adams RA, Brown H, et al. A Bayesian account of 'hysteria'. Brain 2012;135:3495-512.

8 Carson AJ, Brown R, David AS, et al. Functional (conversion) neurological symptoms: research since the millennium. J Neurol Neurosurg Psychiatry 2012;83:842-50.

9 Carson AJ, Stone J, Warlow C, et al. Patients whom neurologists find difficult to help. J Neurol Neurosurg Psychiatry 2004;75:1776-8.

10 Kanaan R, Armstrong D, Barnes P, et al. In the psychiatrist's chair: how neurologists understand conversion disorder. Brain 2009;132:2889-96.

11 Price JR. Managing physical symptoms: the clinical assessment as treatment. J Psychosom Res 2000;48:1-10.

12 Creed F, Guthrie E, Fink P, et al. Is there a better term than 'medically unexplained symptoms'? J Psychosom Res 2010;68:5-8.

13 Stone J. The bare essentials: Functional symptoms in neurology. Pract Neurol 2009;9:179-89.

14 Stone J, Reuber M, Carson A. Functional symptoms in neurology: mimics and chameleons. Pract Neurol 2013;13:104-13.

15 Pareés I, Kojovic M, Pires C, et al. Physical precipitating factors in functional movement disorders. J Neurol Sci 2014;338:174-7.

16 Stone J. Dissociation: what is it and why is it important? Pract Neurol 2006;6:308-13.

17 Stone J, Warlow C, Sharpe M. Functional weakness: clues to mechanism from the nature of onset. J Neurol Neurosurg Psychiatry 2012;83:67-9.

18 Schwabe M, Howell S, Reuber M. Differential diagnosis of seizure disorders: a conversation analytic approach. Soc Sci Med 2007;65:712-24.

19 Reuber M, Jamnadas-Khoda J, Broadhurst M, et al. Psychogenic nonepileptic seizure manifestations reported by patients and witnesses. Epilepsia 2011;52:2028-35.

20 Stone J, Carson AJ. The unbearable lightheadedness of seizing: wilful submission to dissociative (non-epileptic) seizures. J Neurol Neurosurg Psychiatry 2013;84:822-4.

21 Sharpe M, Stone J, Hibberd C, et al. Neurology out-patients with symptoms unexplained by disease: illness beliefs and financial benefits predict 1-year outcome. Psychol Med 2010;40:689-98.

22 Gelauff J, Stone J, Edwards M, et al. The prognosis of functional (psychogenic) motor symptoms: a systematic review. J Neurol Neurosurg Psychiatry 2014;84:220-6.

23 Kranick S, Ekanayake V, Martinez V, et al. Psychopathology and psychogenic movement disorders. Mov Disord 2011;26:1844-50.

24 Stone J, LaFrance WC, Brown R, et al. Conversion disorder: current problems and potential solutions for DSM-5. J Psychosom Res 2011;71:369-76.

25 Daum C, Hubschmid M, Aybek S. The value of 'positive' clinical signs for weakness, sensory and gait disorders in conversion disorder: a systematic and narrative review. J Neurol Neurosurg Psychiatry 2014;85:180-90.
26 Avbersek A, Sisodiya S. Does the primary literature provide support for clinical signs used to distinguish psychogenic nonepileptic seizures from epileptic seizures? J Neurol Neurosurg Psychiatry 2010;81:719-25.

27 McWhirter L, Stone J, Sandercock P, et al. Hoover's sign for the diagnosis of functional weakness: a prospective unblinded cohort study in patients with suspected stroke. J Psychosom Res 2011;71:384-6.

28 Sonoo M. Abductor sign: a reliable new sign to detect unilateral non-organic paresis of the lower limb. J Neurol Neurosurg Psychiatry 2004;73:121-5.

29 Zeuner K, Shoge R, Goldstein S, et al. Accelerometry to distinguish psychogenic from essential or parkinsonian tremor. Neurology 2003;61:548-50.

30 Schrag A, Trimble M, Quinn N, et al. The syndrome of fixed dystonia: an evaluation of 103 patients. Brain A J Neurol 2004;127:2360-72.

31 Fasano A, Valadas A, Bhatia KP, et al. Psychogenic facial movement disorders: clinical features and associated conditions. Mov Disord 2012;27:1544-51.

32 Stins JF, Kempe CL, Hagenaars MA, et al. Attention and postural control in patients with conversion paresis. J Psychosom Res 2015;78:249-54.

33 Chen CS, Lee AW, Karagiannis A, et al. Practical clinical approaches to functional visual loss. J Clin Neurosci 2007;14:1-7.

34 Stone J, Carson A, Duncan R, et al. Which neurological diseases are most likely to be associated with 'symptoms unexplained by organic disease'. J Neurol 2012;259:33-8.

35 Onofrj M, Bonanni L, Manzoli L, et al. Cohort study on somatoform disorders in Parkinson disease and dementia with Lewy bodies. Neurology 2010;74:1598-606.

36 Pareés I, Saifee T, Kojovic M, et al. Functional (psychogenic) symptoms in Parkinson's disease. Mov Disord 2013;28:1622-7.

37 Stone J, Edwards M. Trick or treat? Showing patients with functional (psychogenic) motor symptoms their physical signs. Neurology 2012;79:282-4.

38 American Psychiatric Association. Diagnostic and Statistical Manual of Mental Disorders. 5th edn. (DSM-5TM). Arlington, Virginia: American Psychiatric Press, Inc., 2013.

39 Young WB, Gangal KS, Aponte RJ, et al. Migraine with unilateral motor symptoms: a case-control study. J Neurol Neurosurg Psychiatry 2007;78:600-4.

40 Edwards MJ, Stone J, Lang AE. From psychogenic movement disorder to functional movement disorder: It's time to change the name. Mov Disord 2014;29:849-52.

41 Fahn S, Olanow CW. 'Psychogenic Movement Disorders': They Are What They Are. Mov Disord 2014;29:853-6.

42 Health Improvement Scotland. Stepped care for functional neurological symptoms. Edinburgh, 2012.

43 Edwards MJ, Stone J, Nielsen G. Physiotherapists and patients with functional (psychogenic) motor symptoms: a survey of attitudes and interest. J Neurol Neurosurg Psychiatry 2012;83:655-8.

44 Nielsen G, Stone J, Edwards MJ. Physiotherapy for functional (psychogenic) motor symptoms: a systematic review. J Psychosom Res 2013;75:93-102.

45 Nielsen G, Stone J, Matthews A, et al. Physiotherapy for functional motor disorders: a consensus recommendation. J Neurol Neurosurg Psychiatry 2015;86:1113-19.

46 Sharpe M, Walker J, Williams C, et al. Guided self-help for functional (psychogenic) symptoms: a randomized controlled efficacy trial. Neurology 2011;77:564-72. 
47 Goldstein LH, Chalder T, Chigwedere C, et al. Cognitive-behavioral therapy for psychogenic nonepileptic seizures: a pilot RCT. Neurology 2010;74:1986-94.

48 Hubschmid M, Aybek S, Maccaferri GE, et al. Efficacy of brief interdisciplinary psychotherapeutic intervention for motor conversion disorder and nonepileptic attacks. Gen Hosp Psychiatry 2015;37:448-55.

49 Jordbru AA, Smedstad LM, Klungsøyr O, et al. Psychogenic gait disorder: a randomized controlled trial of physical rehabilitation with one-year follow-up. J Rehabil Med 2014;46:181-7.

50 Nielsen G, Ricciardi L, Demartini B, et al. Outcomes of a 5 -day physiotherapy programme for functional (psychogenic) motor disorders. J Neurol 2015;262:674-81.
51 Saifee TA, Kassavetis P, Pareés I, et al. Inpatient treatment of functional motor symptoms: a long-term follow-up study. J Neurol 2012;259:1958-63.

52 Demartini B, Batla A, Petrochilos P, et al. Multidisciplinary treatment for functional neurological symptoms: a prospective study. J Neurol 2014;261:2370-7.

53 McCormack R, Moriarty J, Mellers JD, et al. Specialist inpatient treatment for severe motor conversion disorder: a retrospective comparative study. J Neurol Neurosurg Psychiatry 2014;85:895-900.

54 Stone J, Hallett M, Carson A, et al. Functional disorders in the Neurology section of ICD-11: a landmark opportunity. Neurology 2014;83:2299-301.

55 World Health Organisation. ICD11 Beta Draft. http://apps. who.int/classifications/icd11/browse/f/en 